\title{
Theoretical basics of applying the one dimensional problem of soils compression seal theory to large foundation plates calculation
}

\author{
Veniamin Isaev ${ }^{1}$, Andrei Maltsev ${ }^{1}$, and Andrei Karpov, ${ }^{1, *}$ \\ ${ }^{1}$ Samara State Technical University, Institute of Architecture and Civil Engineering, \\ Molodogvardeyskaya str. 194, 443001 Samara, Russia
}

\begin{abstract}
Calculation of compressed footings settlement is one of the most vital tasks of soil mechanics. The calculation method of layer-by-layer addition, which recommended by current regulations and used in structural engineering practice, is most suitable for determining the settlement of foundations with an area of less than $50 \mathrm{~m}^{2}$. The authors prove that it's possible to apply the one-dimensional problem of soils compression seal theory to the calculation of the settlement of large foundation plates. The proposed method of determining the settlement of large foundation plates makes the calculations simpler. There are examples of comparable calculations using the existing and proposed methods.
\end{abstract}

\section{Introduction}

Currently in design practice, to calculate the deformations of soil footing, in most cases the theory of linearly deformed half-space is used. It is based on the assumption that the stress propagation zone deep into the soil body from the load applied to the surface is not limited and goes to infinity. However, at great depths the stress of the overlying soil layers' own weight significantly exceeds the additional stress of external load. Therefore, we can assume the following: at a certain depth the soil is already so much compressed by the load of its own weight, that a slight increase in total stress due to the load of a building practically does not cause any additional soil compression. For this reason, in the majority of methods for calculating settlement the thickness of the compressed soil body under the foundation is limited by the layer, under which soil deformations are considered to be minor, and therefore they may not be taken into account. In such a case the compressed width is regarded as the active zone of the soil body under the foundation base, in which the most significant share of the settlement deformation takes place.

\footnotetext{
*Corresponding author: andrkarpow@yandex.ru
} 


\title{
2 Analysis of existing methods of determining compressed width's depth
}

\author{
Notation system: \\ $\mathrm{P}_{0} \quad$ compacting pressure, $\mathrm{kPa}$ \\ $\mathrm{P}$ pressure of the building, $\mathrm{kPa}$ \\ $\gamma \quad$ soil's specific gravity, $\mathrm{kH} / \mathrm{m}^{3}$ \\ d foundation depth, $m$ \\ $\mathrm{z} \quad$ soil body thickness, $\mathrm{m}$ \\ $\sigma_{z p i}$ stress in the soil body caused by the pressure of the building, $\mathrm{\kappa Pa}$ \\ $\sigma_{\text {zgi }}$ stress caused by the soil's own weight, $\mathrm{kPa}$ \\ $\mathrm{R}$ width/length of the rectangular foundation, $\mathrm{m}$ \\ $\mathrm{r}$ «floating» coordinate, $\mathrm{m}$ \\ $\mathrm{H}_{\mathrm{c}} \quad$ compressed width's depth, $\mathrm{m}$ \\ $\beta$ non-dimensional coefficient, equal to 0.8 \\ E soil deformation modulus, $\mathrm{MPa}$ \\ $\mathrm{S}$ foundation settlement, $\mathrm{m}$
}

An analysis of different methods for calculating the compressed width's depth, based on the theory under consideration, was made by Professor P.A. Konovalov [1]. The resulting dependences of the changes in the depth of the active zone's bottom boundary on the foundation's width, obtained using several different calculation methods, are shown on

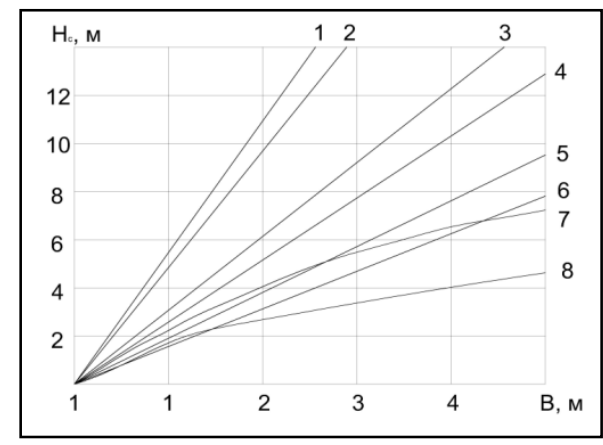

Fig 1. Dependence of the compressed soil width's depth on the size of the square foundation, determined according to different methods: 1- by V.A. Florin; 2- by PlagemanLanger; 3-by N.A. Tsytovich;4- by I.A. Rosenfeld; 5-American method; 6-by E.F. Vinokurov; 7-SNIP 2.02.01-83*;8SNIP II-16-76.

As seen from the graphs presented in Figure 1, the results of the calculation of the compressed width's depth very much, and it's impossible to choose one particular method. Therefore, let us consider in more detail the methods described in SP 22.13330.2011 [2], which is the current normative document.

According to the current normative document [2], it is recommended to calculate foundation settlement, considering the footing as a linearly deformed half-space, here it is meant that a certain layer is compressed (referred to below as the method by K.E. Egorov [3]).

Also settlement calculation is done using the layer-by-layer addition method (referred to below as the method by N.A. Tsytovich [4]), which has got the following assumptions:

- the calculation of settlement is made for the central point of the foundation, taking into account axial compression stresses; 
- the compressed layer is defined as the distance from the foundation base to the point in the soil body, at which the certain defined ratio of compacting and overburden pressure values is met;

- the compressed layer is divided into elementary layers, and the compression seal principle is applied to each of these layers;

- the compression of the elementary layer of soil takes place under the pressure of the building, net of the existing overburden pressure.

The term "compacting pressure", or "overpressure", applies in case the foundation has got some laying depth. When this occurs the value of the pressure of own weight of the soil excavated to the foundation base is deducted from the actual pressure of the building on the foundation base. This is expressed by the formula (1)

$$
P_{0}=P-\gamma \cdot d
$$

\section{Justification of the possibility to apply the one dimensional problem of soils compression seal theory to large foundation plates calculation}

From the works [3-10] it's known that the layer-by-layer addition method is most suitable for determining the settlement of foundations with an area of less than $50 \mathrm{~m}^{2}$.

To apply the principle of one-dimensional soils compression seal to calculate the settlement of large foundation plates it's necessary to prove the following:

- under the plates there's compressed width of insignificant depth;

- compacting pressure is uniformly distributed along the layer height over the entire area;

- uniformly distributed load under the plate extends sideways to infinity.

The size of the compressed layer, according to N.A. Tsytovich [4], is defined as the distance from the surface of load application to the point (horizon), where such load is equal to zero.

According to the theory of linearly deformed half-space, the stresses in the half-space attenuate at infinity.

However, in reality, the impact of the load of the building is over at the depth (on the horizontal plane), where such load is balanced by the weight of excavated soil, which is expressed by the formula:

$$
P_{0}=\gamma \cdot z
$$

If the foundation has got some definite laying depth, the formula changes to:

$$
P_{0}=\gamma \cdot(z-d)
$$

Thus, the soil body the width of which is $\mathrm{z}$ will experience the compression caused by the actual load $\mathrm{P}$ applied to the surface, and in this case the width $\mathrm{Z}$ can be called the compressed width.

Since all foundations are designed with the laying depth d given in advance, the value of the compressed width is found from the expression:

$$
H_{c}=z-d=\frac{P}{\gamma}-d
$$


To prove the uniform distribution of stresses along the height of the linearly deformed layer, let's consider the well-known solution of the theory of elasticity for stresses under round rigid stamp [4]:

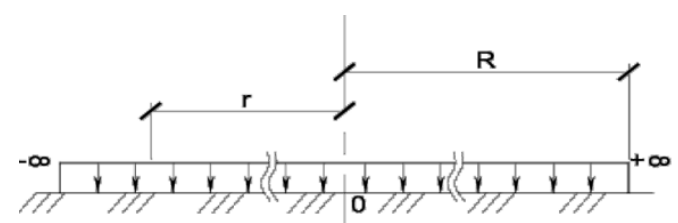

Fig 2. Design diagram for determining the uniform distribution of stresses under very big foundations.

$$
\sigma_{z p i}=\frac{P}{2 \cdot \sqrt{1-\left(\frac{r}{R}\right)^{2}}}
$$

Where at $r=0$ (under the foundation's centre) the formula changes to:

$$
\sigma_{z p i}=\frac{P}{2 \cdot \sqrt{1-\left(\frac{0}{R}\right)^{2}}}=\frac{P}{2}
$$

For distributed load, which extends sideways to infinity and passes through a large foundation plate, the latter's width in the calculation is taken as an infinite value. After substituting $\mathrm{R}=\infty \mathrm{B}$ in formula (5) we get the stress values, similar to formula (6):

$$
\sigma_{z p i}=\frac{P}{2 \cdot \sqrt{1-\left(\frac{0}{R}\right)^{2}}}=\frac{P}{2}
$$

The comparison of formula (6) and formula (7) demonstrates the uniform distribution of compacting pressures along the layer height under the entire area of the plate, which proves one-dimensional soils compression seal of the compression width.

The above-given proof allows using the formula of the one-dimensional problem for large plates [4]:

$$
S=H_{c} \cdot P \cdot \frac{\beta}{E}
$$

\section{Examples of calculations}

As an example of using the one-dimensional problem of soils compression seal theory for large foundation plates calculation, below we give the calculations of settlement of two foundation plates under a 10-storey apartment building in the city of Samara.

Example №1. The foundation is a plate of square shape, side length $=18.0 \mathrm{~m}$, actual soil bearing pressure $\mathrm{P}=176 \mathrm{kPa}$, loam, width $=12.5 \mathrm{~m}$, specific gravity $\gamma=19.8 \mathrm{kH} / \mathrm{m}^{3}$, deformation modulus $\mathrm{E}=10 \mathrm{MPa}$. Laying depth of plate $\mathrm{d}=4.0 \mathrm{~m}$

The calculation results according to the proposed method:

-compressed width from formula (4) 


$$
H_{c}=\frac{176}{19.8}-4.0=4.9 m
$$

- settlement according to formula (8):

$$
S=176 \cdot 4.9 \cdot \frac{0.8}{10000}=0.069 m
$$

For comparison:

Calculation results according to the method by K.E. Egorov: $\mathrm{H}_{\mathrm{c}}=10.42 \mathrm{~m}, \mathrm{~S}=0.069 \mathrm{~m}$.

Calculation results according to the layer-by-layer addition method: compressed width's depth at $\sigma_{\text {zpi }}=85 \mathrm{kPa}, \sigma_{\mathrm{zgi}}=170 \mathrm{kPa}-\mathrm{H}_{\mathrm{c}}=4.3 \mathrm{~m}$; settlement at $\mathrm{P}_{0}=96.8 \mathrm{kPa}-\mathrm{S}=0.03 \mathrm{~m}$.

Example №2. The foundation is a plate with the side length of $19.2 \mathrm{~m}$, the actual pressure under the foundation base is $\mathrm{P}=156 \mathrm{kPa}$. Soil conditions are similar to example №1.

The calculation results according to the proposed method:

-compressed width from formula (4)

$$
H_{c}=\frac{156}{19.8}-4.0=3.9 M
$$

- settlement according to formula (8):

$$
S=156 \cdot 3.9 \cdot \frac{0.8}{10000}=0.05 M
$$

For comparison:

Calculation results according to the method by K.E. Egorov: $H_{c}=10.21 \mathrm{~m}, \mathrm{~S}=6.49 \mathrm{~cm}$.

Calculation results according to the layer-by-layer addition method: compressed width's depth at $\sigma_{\text {zpi }}=70 \mathrm{kPa}, \sigma_{\mathrm{zgi}}=140 \mathrm{kPa}-\mathrm{H}_{\mathrm{c}}=3.2 \mathrm{~m}$; settlement at $\mathrm{P}_{0}=76.8 \mathrm{kPa}-\mathrm{S}=0.02 \mathrm{~m}$.

\section{Conclusion}

Finally, it can be concluded that the proposed method of determining the settlement of large foundation plates makes the calculations simpler. In the future, the authors intend to specify the field of application of the method (plate size) - of the one-dimensional problem of soils compression seal, as well as to confirm the proposed theory by experiment.

\section{References}

1. P.A. Konovalov, Footings and foundations of renovated buildings, 4th edition (VNIINTPI, Bumazhnaya Galereia Publisher, Moscow, 2000)

2. SP 22.13330.2011 Footings of buildings and structures (Ministry of Regional Development of the Russian Federation, Moscow, 2011)

3. K.E. Egorov, On deformation of finite footings: footings, foundations and soil mechanics (Moscow, 1961)

4. N.A. Tsytovich, Soil mechanics, comprehensive study, 5th edition (Lenand Publisher, Moscow, 2014)

5. V.I. Isaev, O.M. Kakutina, A.V. Maltsev, On sealing of water-saturated clay soils, Vital problems in civil engineering and architecture, Education, science, practice: 
Proceedings of the 66th all-Russian scientific and technical conference on $R \& D$ results in 2008, part II (SGASU, Samara, 2009)

6. A.V. Maltsev, T.O. Klokova, Analysis of areas for efficient application of methods to calculate linearly deformed footings settlement, Vital problems in civil engineering and architecture, Education, science, practice: Proceedings of the 66th all-Russian scientific and technical conference on R\&D results in 2008, part II (SGASU, Samara, 2009)

7. A.V. Maltsev, D.G. Skopintsev, Proceedings of the 59th regional scientific and technical conference in April 2, $412-414$ (2002)

8. A.V. Maltsev, D.G. Skopintsev, Vital problems in civil engineering and architecture, Education, science, practice: Proceedings of the 60th all-Russian scientific and technical conference on R\&D results in 2002, part II, 230-234 (2003)

9. A.A. Averkiev, O.V. Zayats, Tradition and innovation in civil engineering and architecture: Proceedings of the 69th all-Russian scientific and technical conference on R\&D results in 2011, part 2, 422-423 (2012)

10. A.V. Maltsev, N.O. Tolmachev, I.V. Tikhonov, Tradition and innovation in civil engineering and architecture: Proceedings of the 70th anniversary all-Russian scientific and technical conference on R\&D results in 2012, part 2, 378-379 (2013) 